\title{
Using 2D imaging resistivity and Bristow's method to detect the weak zones under College of Science (Anbar University)/West of Iraq
}

\author{
Ali Mishaal Abed* \\ Department of Applied Geology. Collage of Science, Anber University, Ramadi, Iraq
}

A R T I C LE INFO

Article history:

Received 18 August 2016

Accepted 16 November 2016

Keywords:

A-spacing;

Bristow's method;

Dipole-dipole array;

$n$-factor;

Resistivity imaging.

\begin{abstract}
A B S T R A C T
The study area is located inside Anbar University, West of Iraq. The measurements of two dimension (2D) imaging resistivity survey were carried out along traverse W-E direction $(50 \mathrm{~m})$ by using Dipole-dipole array, with pole distance(a) and $\mathrm{n}$-factor of $2 \mathrm{~m}$ and (6) respectively, to delineate the anomaly in apparent resistivity caused by subsurface weak zone, which has got small slip side of Biology department building, within gypsum rocks( Fatha Formation, Middle Miocene). Graphical Bristow's method data was conducted along the same traverse with $70 \mathrm{~m}$, by using Pole-dipole array. Dipole-dipole array (2D) is done with n-factor of 6 and a-spacing equals $2 \mathrm{~m}$. The inverse models of $2 \mathrm{D}$ resistivity technique clearly showed that the resistivity contrast between the anomalous part of cavity and background resistivity is about 700:100 $\Omega \mathrm{m}$. The subsurface weak zone is well defined from 2D imaging resistivity survey with Dipole-dipole array, the depth to weak zone is located at $10.2 \mathrm{~m}$ from the ground surface and dimensions equal $3.4 \mathrm{~m}$ height and $9.5 \mathrm{~m}$ width. Data interpretation of the Pole-dipole (Bristow's method) traverse, with a-spacing equal to (2m) identified the anomaly of the weak zone is located at $9.5 \mathrm{~m}$ depth, $3 \mathrm{~m}$ height, and $12 \mathrm{~m}$ width. Because of a-spacing effect on the determinations accurate. Therefor it must be taken into consideration in choosing in the field before taking the measurements by using Bristow's method. The 2D imaging resistivity technique is using the suitable a-electrode spacing and $\mathrm{n}$-factor for the Dipole -dipole array which provides the best subsurface model.
\end{abstract}

\section{Introduction}

Detection and delineation of subsurface weak zones, and forsaken tunnels using geophysical methods have earned wide interest in the last few decades. These methods include electrical resistivity, electromagnetic, gravimetric, seismic techniques and recently ground penetrating radar (GPR) method. Of these methods, the electrical resistivity has been the most extensive in detecting cavity ${ }^{[1]}$.

There are some previous studies in Iraq that used resistivity method for detecting subsurface cavities, such as Al-Ane ${ }^{[2]}$ that used Wenner array to detect the cavities in Hmam Al-Alel area, north Iraq. The Resistivity map was drawn, and displayed high positive anomalies, where the cavities were present within gypsum rocks. Al-Gabery ${ }^{[3]}$ measured two sounding stations, one over the known cave in Rawa area (WestIraq), and the other is carried out at a distance of $80 \mathrm{~m}$ west of the cave using Wenner and Schlumberger arrays.

* Corresponding author.

E-mail address: ali_mishal2001@yahoo.com
Also, twelve horizontal profiles, along each profile the resistivity measurements were carried out using Wenner, Schlumberger and Pole-dipole (Bristow's method) arrays. The best result was obtained from the Pole-dipole array by using graphical Bristow method. Abed ${ }^{[4]}$ and Thabit and Abed ${ }^{[5]}$ compare between the two dimension (2D) imaging resistivity survey and Bristow's method in detecting the accurate depth and shape of subsurface cavities which is located within Haditha-Hit area, western Iraq. 2D imaging resistivity surveys are done along four traverses in Hit area. Dipole-dipole (n-factor $=6$ and 8$)$, Wenner-Schlumberger $(\mathrm{n}=8)$, and Pole-dipole $(\mathrm{n}=8)$ arrays are applied along traverse above Um ElGithoaa cavity. Another Dipole-dipole $(n=6)$ array is carried out along a traverse in Haditha area above Wadhaha Shamut cavity.

Graphical Bristow's method that is based upon direct interpretation techniques was measured with potential electrode spacing of $2 \mathrm{~m}$ above the same traverse. Graphical Bristow's method and 2D imaging resistivity surveys are proved to be able to detect subsurface 
cavities and voids. Thabit et al. ${ }^{[6]}$ used 3D resistivity imaging survey which was carried out over Um ElGithoaa cavity in Hit area, west Iraq. Resistivity data were collected along four parallel traverses using Dipole-dipole array with electrode spacing of $(2 \mathrm{~m})$ and (n) factor equal to 6. Inverted 3D models obtained from standard least-squares method and robust constrain method at Um El-Githoaa cave showed horizontal slices of the 3D resistivity distribution with depth. The comparison between the two methods of inversion appeared that the inverse model produced by the robust constrain method has sharper and straighter boundaries. Abed ${ }^{[7]}$ used Graphical Bristow's method across K-3 cave to evaluate the method to detect the dimension of a relatively large natural cave. The data interpretation detect the cavity elongate along West -East traverse of about $58.6 \mathrm{~m}$ with an error not exceeded $3 \%$ in depth and $2 \%$ in height. While Abed and Thabit ${ }^{[8]}$ conducted 2D imaging resistivity survey across an unknown K-3 cavity that is located in Haditha area-Western Iraq. 2D measurements are collected along two intercrossing traverses above the cavity with $105 \mathrm{~m}$ length of each one. Dipole-dipole array is performed with n-factor of 6 and a-spacing equals to $5 \mathrm{~m}$. The K-3 cavity is well defined from 2D imaging resistivity survey with selected Dipole -dipole array in comparison with the actual depth of thiscavity which equals to $11.5 \mathrm{~m}$ approximately.

Most 2D (Two Dimension) imaging surveys had been used for shallow engineering and environmental studies, these techniques are used to detect the subsurface cavities in the world ${ }^{[9]}$. 2D imaging resistivity is considered as one of the most powerful techniques to detect cavities in karst region, due to it low coast and high resistivity contrast between the cavity and the background formation ${ }^{[10]}$. The purpose of this study is to detect the subsurface weak zones within Anbar University which is caused a small slide slip of Biology Department building, by using Bristow's method and 2D resistivity imaging techniques.

\section{Materials and Methods}

\section{Geography and geology of study area:}

The study area is located within Anbar university- west Iraq (N 33 $24^{\prime} 10.54 "$, E $\left.43^{\circ} 15^{\prime} 46.53 "\right)$. Subsurface weak zone, within Fatha Formation (Middle Miocene) beside the Biology department, Science College which has got small slip side (Fig. 1). Fatha Formation is one of the most aerially widespread and economically important formations in Iraq, it includes sinkholes and cavities within gypsum rock ${ }^{[11]}$. It comprises of anhydrite, gypsum, and salt deposits, interbedded with limestone and marl ${ }^{[12]}$, as shown in (Fig. 2).

\section{Selection of array parameters:}

The main object of these parameters is to select the suitable sequence to achieve real subsurface imaging. In 2D imaging resistivity each array has advantages and disadvantages for investigation depth, data coverage, signal strength, and sensitivity function to vertical and horizontal change in resistivity ${ }^{[13]}$. In Dipole-dipole array, when the n-factor changes from 1 to 6 , , the maximum estimated depth of investigation reaches $8.29 \mathrm{~m}$ with coverage data equals to 204 reading.

Bristow (1966) applied modified method of the poledipole array in a manner which allowed direct graphical interpretation of the cavity dimensions ${ }^{[14]}$. Bates ${ }^{[15]}$ has applied Bristow's method to delineate a number of known cavities, after making some slight modification; he was also able to locate a relatively small target cavity.

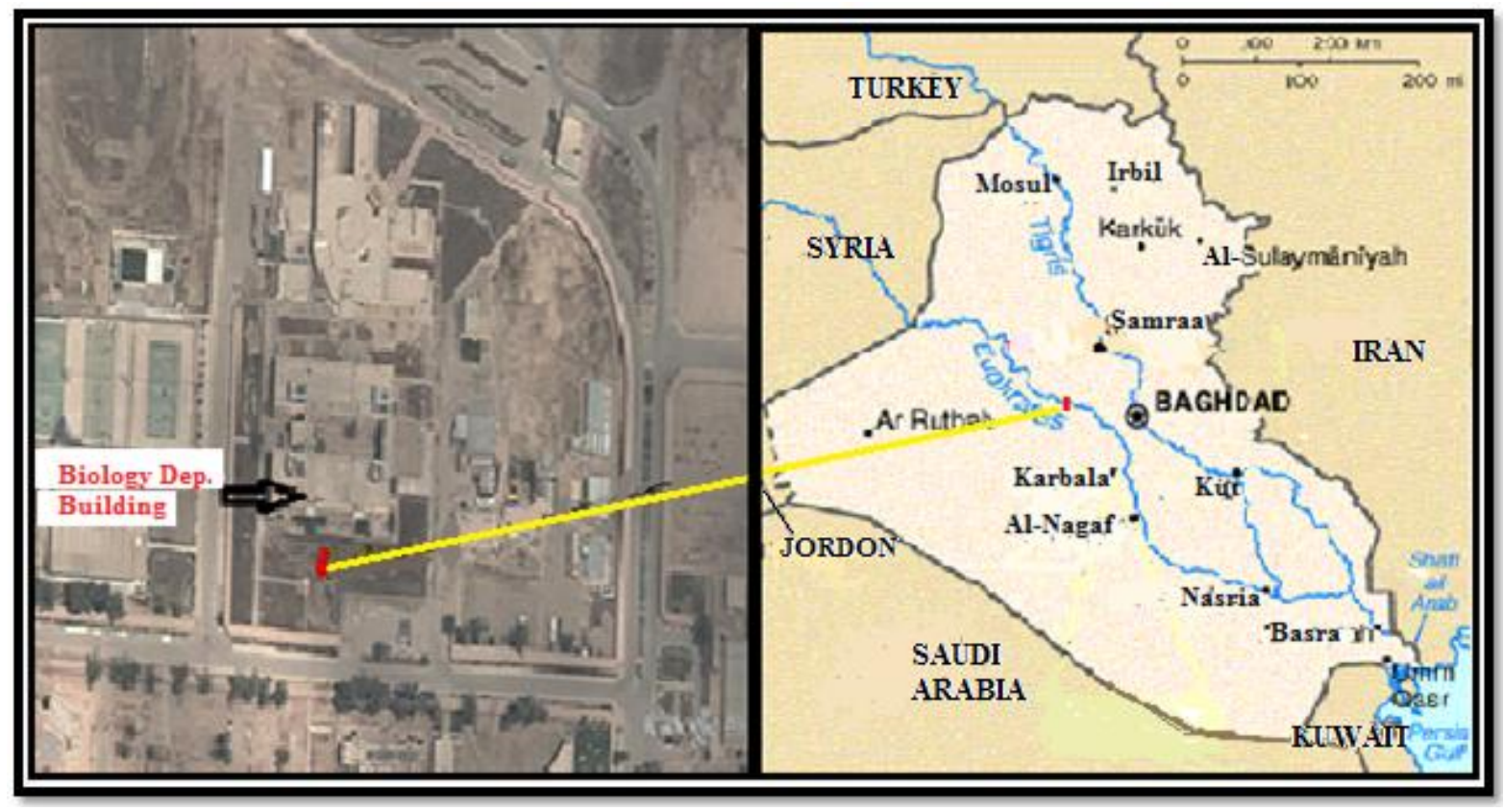

Fig. (1): Location map of the study area. 


\begin{tabular}{|c|c|c|c|c|c|}
\hline \multicolumn{2}{|c|}{$\begin{array}{l}\text { Depth } \\
\text { (m) }\end{array}$} & \multirow{2}{*}{$\begin{array}{c}\text { Thickness } \\
\text { (m) }\end{array}$} & \multirow[t]{2}{*}{ Brief Description } & \multirow{2}{*}{$\begin{array}{l}\text { Lat : } 33^{\circ} 20^{\prime} 27^{\prime \prime} \mathrm{N} \\
\text { Long : } 43^{3} 15^{\prime} 47 \mathrm{E} \\
\text { Elevation : } 57.37 \mathrm{~m}\end{array}$} & \multirow{2}{*}{$\begin{array}{l}\text { BH-CDS-1 } \\
\text { LITHOLOGY }\end{array}$} \\
\hline From & To & & & & \\
\hline 0.0 & 1.5 & 1.5 & Gypsiferous soil and gypsum & & \\
\hline 1.5 & 7.6 & 6.1 & Pale brown claystone & & \\
\hline 7.6 & 15.2 & 7.6 & Claystone with gypsum & & \\
\hline 15.2 & 19.0 & 3.8 & Pinkish pale claystone & & \\
\hline 19.0 & 22.6 & 3.6 & Silty claystone with limestone & & \\
\hline 22.6 & 34.2 & 13.6 & Claystone with siltstone & & \\
\hline 34.2 & 38.0 & 3.8 & Silty gypsiferous siltstone & & \\
\hline 38.0 & 45.3 & 7.3 & Clayey gypsiferous limestone & & \\
\hline 45.3 & \begin{tabular}{|l|}
63.9 \\
\end{tabular} & 18.6 & White gypsum & & \\
\hline 63.9 & \begin{tabular}{|l|}
67.2 \\
\end{tabular} & 3.3 & Brown claystone with gypsum & & \\
\hline 67.2 & 71.0 & 3.8 & Green marl & & \\
\hline 71.0 & $\mathbf{7 4 . 7}$ & 3.7 & Gypsum & & \\
\hline $\mathbf{7 4 . 7}$ & 76 & 1.3 & Gypsum with green marl & & \\
\hline 76 & 79.6 & 3.6 & Marly gypsiferous limestone & & \\
\hline 79.6 & 87.3 & 7.7 & White gypsum withmarl & & \\
\hline 87.3 & 102.2 & 14.9 & Limestone with gypsum & & $=$ \\
\hline 102.2 & 117.2 & 15.0 & Limestone with marly gypsum & & \\
\hline 117.2 & 138.0 & 20.2 & Marly limestone with gypsum & & \\
\hline 138.0 & 142.5 & 4.5 & Grey marl & & \\
\hline 142.5 & 160.5 & 18 & Grey marl and marly limestne & & \\
\hline 160.5 & 185 & 24.5 & $\begin{array}{l}\text { Marly Limestone with } \\
\text { fossiliferous limestone }\end{array}$ & & \\
\hline 185 & 194 & 9.0 & Chalkylimestone andlimestone & & \\
\hline 194 & 200 & 6.0 & Marly limestone & & \\
\hline
\end{tabular}

Fig. (2): Detailed lithologic section on UON area ${ }^{[12]}$.

Several field examinations of Bristow's method had been conducted with various degrees of success by Fountain et al. ${ }^{[16]}$; Greedy ${ }^{[17]}$; Myers ${ }^{[18]}$; Kirk and Werner $^{[19]}$; Ushijima et al. ${ }^{[20]}$ and Elawadi et al. ${ }^{[21]}$. The a-spacing is a very important factor on the accurate determination of the subsurface weak zones dimensions. So, it must be chosen carefully when using Bristow's method. The Pole-dipole array used two current $\left(\mathrm{C}_{1}\right.$ and $\left.\mathrm{C}_{2}\right)$ and two potential electrodes $\left(\mathrm{P}_{1}\right.$ and $\left.\mathrm{P}_{2}\right)$ arranged along straight line. One current electrode is placed at distance effective infinity, which is greater than five to ten times the length of distance $\left(\mathrm{P}_{1}, \mathrm{C}_{2}\right)$ and the survey line. The two potential electrodes are located at affixed separation equal to (a) spacing. The potential difference is measured between the two potential electrodes, by moving current electrode $\left(\mathrm{C}_{1}\right)$ incrementally with $(\mathrm{n}=1$, $2, \ldots)$ for a distance (na) equal approximately to (10a) on either side of the local current electrode $\left(C_{1}\right)$, and along the traverse. A-spacing must be taken into consideration when using Bristow's method. On a scale drawing of the vertical section along the survey line, an intersection of two or more equipotential hemispherical shells having radii corresponding to the current to potential electrode separation distance at which resistivity anomalies are observed will locate the subsurface cavity (Figure 3).

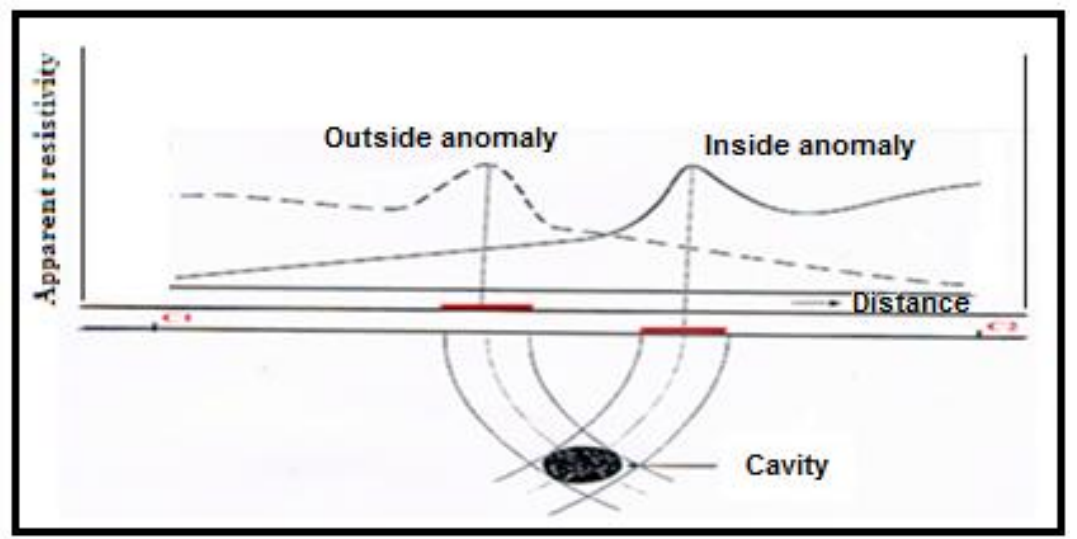

Fig. (3): Graphic interpretation procedure of Pole-dipole (Bristow's method) resistivity data ${ }^{[21]}$. 


\section{Field work:}

2D imaging resistivity survey (Dipole-pole array) and Bristow s (Pole-dipole array) methods are used to collect apparent resistivity data along WE traverse. The Terrameter SAS (4000) instrument was used for measuring apparent resistivity in the field (Fig. 4).

2D imaging resistivity survey is done along the same traverse of Bristow's array which runs beside the southern side of the Biology department building. In the present study, 2D resistivity measurements are carried out manually, and the data are also interpreted manually by the RES2DINVsoftware through IPI2win software. The 2D survey was carried out by Dipole-dipole (nfactor $=6$ ), When the data is collected by these array the maximum electrode spacing (a) is equal (2m) with a total array length of $(50 \mathrm{~m})$.

The field layout of Bristow's method: the Current electrodes $\left(C_{1}\right.$ and $\left.C_{2}\right)$ of Pole- dipole were planted along the traverse W-E with $(70 \mathrm{~m})$ separation, and the potential measurements were collected with interval spacing (a) of potential electrodes $\left(\mathrm{P}_{1}, \mathrm{P}_{2}\right)$ equal to $(2 \mathrm{~m})$, and moving incrementally over intervals of $(9 n)$.

\section{Results}

\section{D resistivity imaging profile}

The bad data is usually more common with the Dipoledipole array that has very large geometric factors. The conventional least-squares method is used to minimize the square of difference between the values of measured and calculated apparent resistivity ${ }^{[22]}$.

This method normally gives reasonable results if the data contains random noise come from the effect of telluric current. However if the data set contains nonrandom (systematic) noise from sources such as measure mistakes or field equipment problems, this situation is less various, and such data points could have a great effect on the resulting inversion model. To reduce the influence of such data points can be applied the absolute difference which is the first power of an inversion method between the measured and calculated apparent resistivity values ${ }^{[23]}$.

$2 \mathrm{D}$ imaging resistivity data were interpreted using the
RES2DINV program (Geotomo Software) version $3.56 .22^{[24]}$. The apparent resistivity values are calculated by forward modeling, and non-linear least-squares optimization tech is utilize for inversion of data ${ }^{[25]}$. Apparent resistivity measurements of $2 \mathrm{D}$ resistivity imaging need further process to model the true distribution of resistivity values for the specific geology. The Inversion programs use mathematical algorithms to produce a subsurface resistivity model that will best fit with the apparent resistivity data set. To overcome the problem of non-uniqueness (many models fit the data equally well), the regularized least-squares optimization method is commonly used in the inversion algorithms [26].

If a relatively larger damping factor (for example 0.3 ) is used, the data set is very noisy. While a smaller initial damping factor (for example 0.1) is used, the data set is less noisy, as mentioned in Loke ${ }^{[13]}$. Here because of noisier data near surface, a higher initial damping factor (0.15) was used, and higher minimum damping factor (0.02) was used. Additionally a higher damping factor (2.5) was used for the first layer.

Another important sub option is (Vertical / Horizontal flatness filter) ratio weight of 1 . If the main anomalies in apparent resistivity pseudo section are elongated horizontally, it must choose a smaller weight than vertical filter ${ }^{[13]}$. So, the flatness filter 0.5 was used weight of.

The inversion results of 2D imaging resistivity Dipoledipole data along the traverse are shown in (Fig. 5), it clearly indicates that the resistivity contrast between the anomalous part of cavity and background resistivity is about 700:100 $\Omega \mathrm{m}$. The inverse model produced by the standard least-squares method has a gradational boundary for the cavity (Fig. 5).

From the inverse model (Fig. 5), the Dimensions of the cave appeared approximately equal to $3.4 \mathrm{~m}$ height, and $9.5 \mathrm{~m}$ width and it located at depth $10.2 \mathrm{~m}$ from the ground surface. The RMS error is fairly high which equal to $5.3 \%$ of this model, may be caused by in homogeneity of Gypsum rocks near the surface.

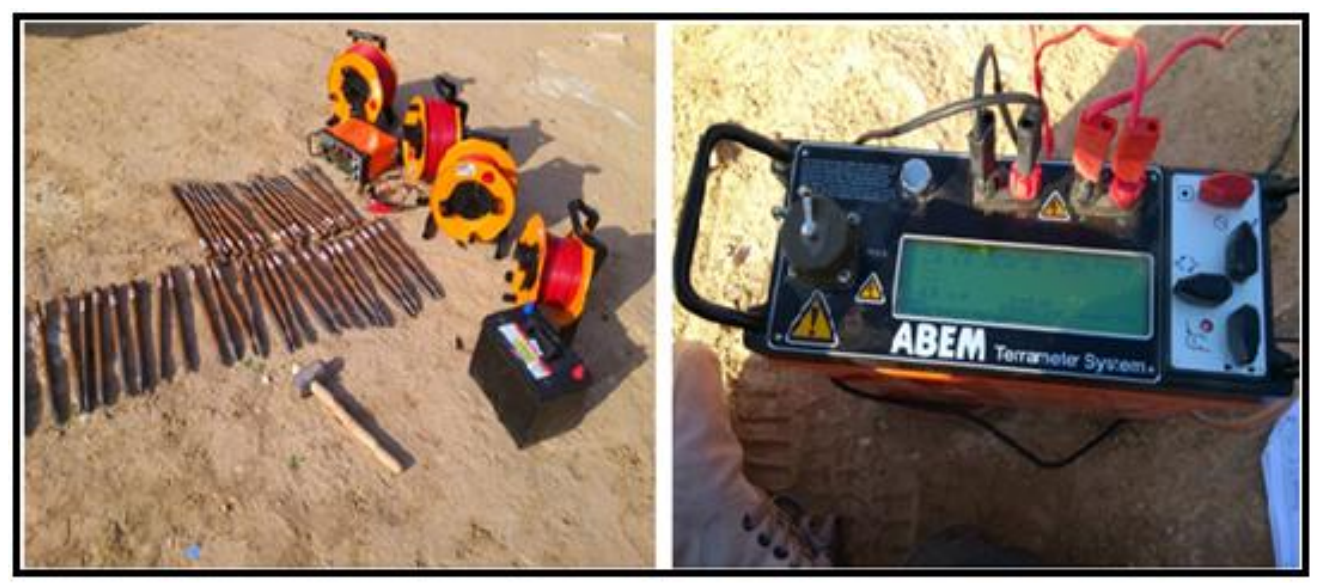

Fig. (4): Field instruments (SAS 4000 / SAS 1000). 


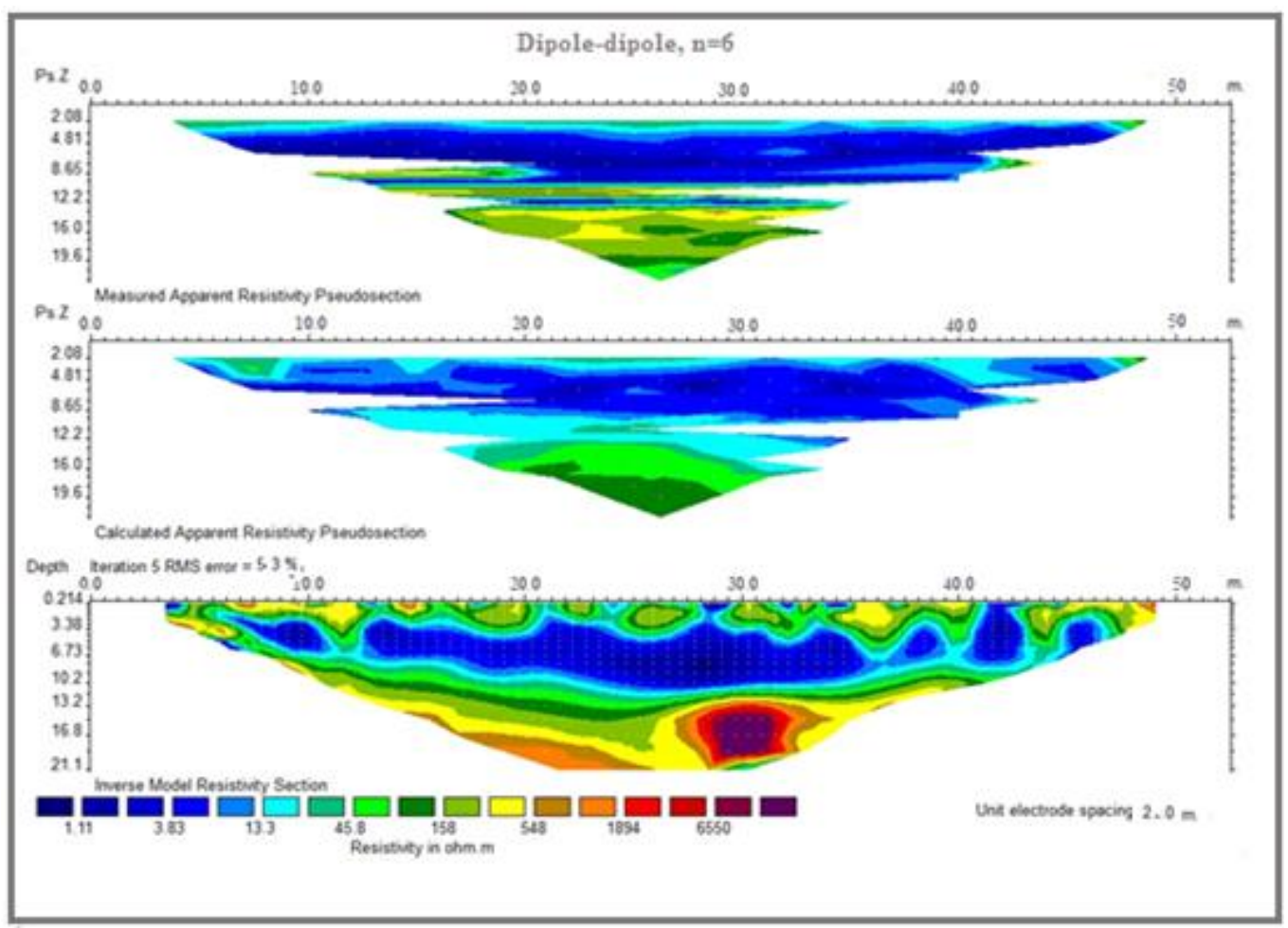

Fig. (5): Measured and calculated pseudo sections and inverse model of Dipole-dipole resistivity section along the W-E traverse (Standard least-squares inversion method).

\section{Bristow's method:}

The Pole-dipole apparent resistivity measurements are presented as pseudosection to show lateral and vertical variations in resistivity with depths, as shown in (Fig. 6). The pseudosection shows anomalous results with high apparent resistivity, which is considered as an indication of subsurface weak zone. The actual size and location of this subsurface zone can be delineated by the graphical interpretation of the resistivity profiles using the Bristow's method (Fig. 7).

Figure (6) shows the pseudosection of apparent resistivity of the data interpretation of the Pole-dipole measurements (Bristow's method) along W-E traverse, with a-spacing of (2m). It appears increasing in apparent resistivity values near the position of the subsurface weak zone reaching approximately (240-300 $\Omega . m$ ); this may reflect the presence of the fracture of the cavity near the middle-distance of the traverse line. The upper part of (Fig. 7) shows the Maximum residual resistivity anomalies ranging between (20-30 $\Omega . \mathrm{m})$. Graphical interpretation of the Pole-dipole data acquired along this traverse, at the lower part of Figure 7, shows the circular arcs are drawn around each current station at radii corresponding to higher resistance perturbations, than the average apparent resistivity of the host medium, which are represented a shallow moisture sedimentary rocks. Results of the traverse along W-E traverse, with aspacing equal to $(2 \mathrm{~m})$ identified the anomaly of the subsurface weak zone of $(9.5 \mathrm{~m})$ depth, $(3.0 \mathrm{~m})$ height from roof of the weak zone to its bottom, and (12m) width.

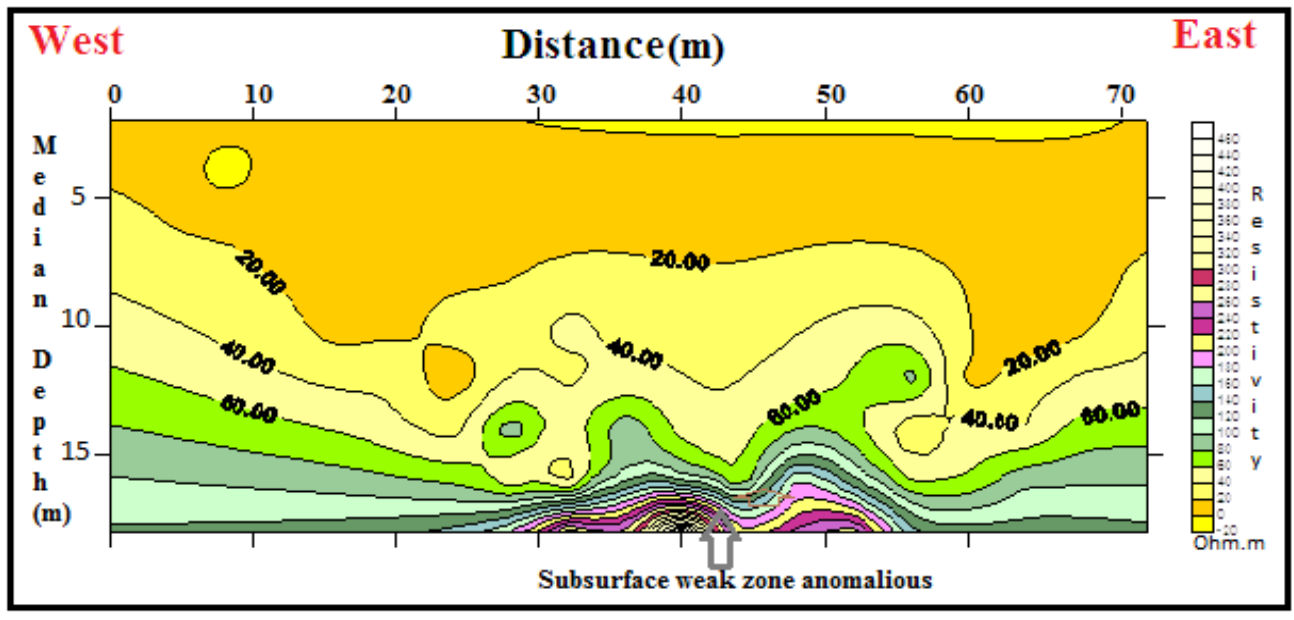

Fig. (6): Field instruments (SAS 4000 / SAS 1000). 


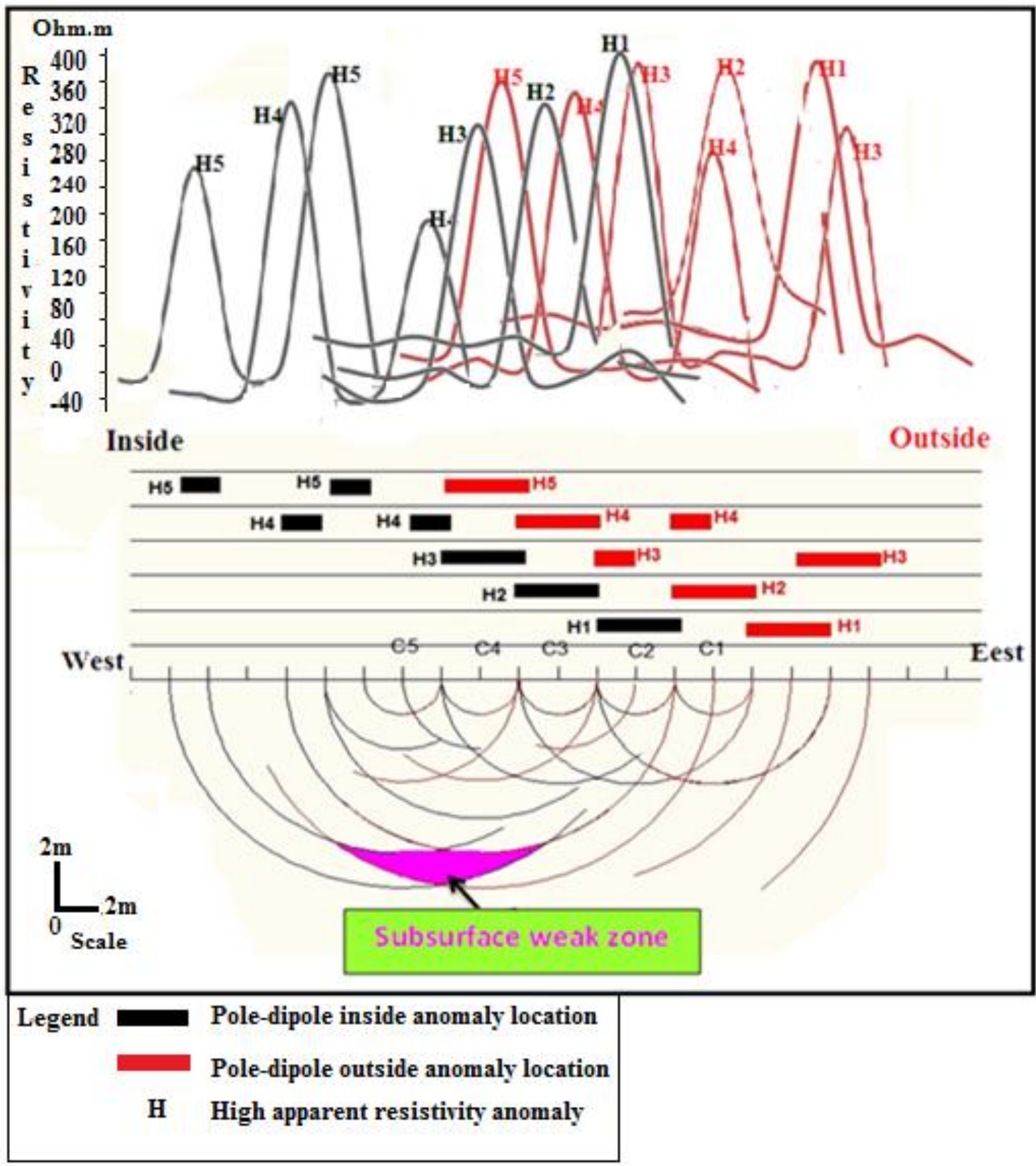

Fig. (7): Intersecting arcs and interpreted anomaly location for the Bristow's method along the W-E traverse with $\mathrm{a}=2$.

\section{Discussion}

The inverse model (2D imaging resistivity survey) shows the lateral and vertical variations in the resistivity values and thickness of shallow horizon. The variations disappear with the results of Bristow's method, and the measurements are very dense in the $2 \mathrm{D}$ imaging surveys (Fig. 8). Choosing potential electrode spacing (a) is very important in Bristow's method and 2D imaging surveys in the accurate detection and locating of the weak zone. The relationship between the cavity and the whole rocks is the best explained in the display of $2 \mathrm{D}$ inversion resistivity model section than what is obtained from Bristow's method. Bristow's method and 2D imaging survey are proved to be able to detect subsurface weak zones, cavities and voids.

The relationship between the cavity and the whole rocks is the best explained in the display of $2 \mathrm{D}$ inversion model resistivity section than what is obtained from Bristow's method. Bristow's method and 2D imaging survey are proved to be able to detect subsurface wake zones, cavities and voids.

\section{Acknowledgments}

The author is grateful to thank the Science College and the staff of Applied Geology Department - Anbar University for providing requirements for achieving the field work. 


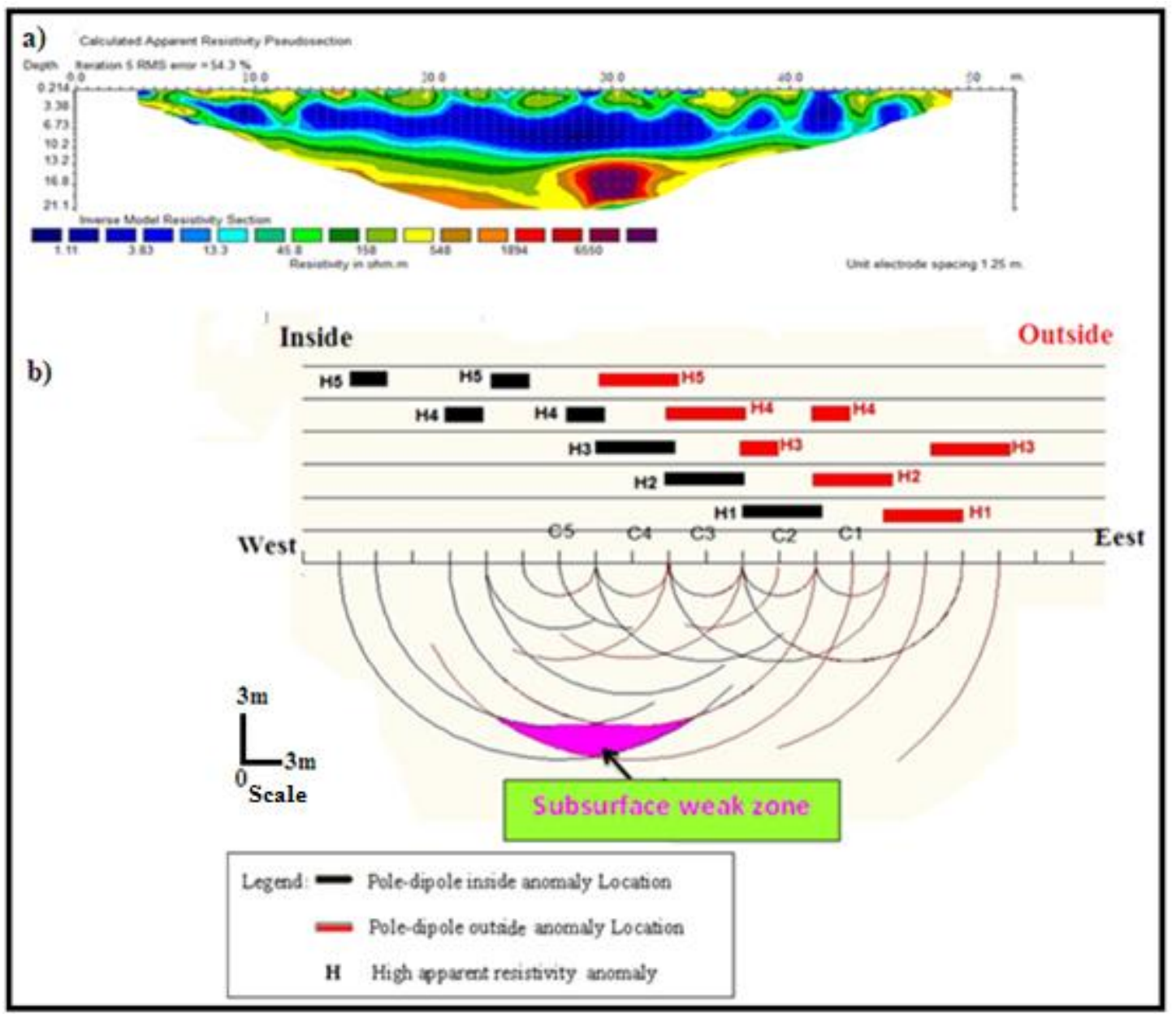

Fig. (8): Comparison between Bristow's method and 2D imaging survey along the W-E traverse: a) 2D imaging survey, b) Graphical method survey.

\section{References}

1) Smith D. L. (1986). Application of the pole-dipole resistivity technique to the detection of solution cavities beneath highways. Geophysics. 51: 833837.

2) Al-Ane, J. M. (1993). Detection subsurface cavities by using the electrical resistivity method in Hamam AL-Alel area, Jour. Geol. Soc. Iraq . 26 (1): 13-26.

3) Al-Gabery, A. S. M. (1997). Geophysical application for engineering purpose-site study, $\mathrm{PhD}$ Thesis, University of Baghdad, Baghdad, Iraq.

4) Abed, A. M. (2013). Comparison between 2D imaging survey and traditional electrode arrays in delineating subsurface cavities in Haditha-Hit area (W Iraq), PhD Thesis University of Baghdad, Baghdad, Iraq.

5) Thabit, J. M. and Abed, A. M. (2013). Evaluation of different electrode arrays in delineation subsurface cavities by using 2D imaging technique, J. of university of Anbar for pure science. 7(3):166-175.

6) Thabit, J. M., Abed, A. M. and AL-Menshed, F. H. (2015). 3D resistivity imaging survey to delineate Um El-Githoaa cavity in Hit area, Western Iraq, Tikrit Journal of pure science. 20(2):135-141.
7) Abed, A. B. (2015). Evaluation of Pole-dipole technique (Bristow's method) to detect the dimension of K-3 cave in Haditha area -west Iraq- Case study, Kirkuk University Journal-Scientific Studies (KUJSS). 10(3):108-121.

8) Abed, A. M. and Thabit, J. M. (2016). Delineation of K-3 Cavity Using 2D Imaging Resistivity Technique in Haditha Area (Western Iraq), Iraqi Journal of Science. 57(1A):209-217.

9) Satarugsa, P., Meesawat, N., Manjai, D. Yangsanpo, S. and Arjwech, R. (2004). Man-made cavity imaging with 2D resistivity technique. International conference on applied geophysics. P. 203-210.

10) Van Schoor, M. (2002). Detection of sinkholes using 2D electrical resistivity imaging, Journal of Applied Geophysics. 50:393- 399.

11) Jassim, S. Z. and Goff, J. (2006). Geology of Iraq. Dolin, Prague and Moravian Museum, Brno.341p.

12) Hussein, B. M. H. (2012). Litho logy of Anbar University area, Unv. of Anbar - ' Center of desert studies $12 \mathrm{P}$. 
13) Loke, M. H. (2015). Tutorial: 2-D and 3D Electrical imaging surveys, email: mhloke@yahoo.com, geotomo@gmail.com.172p.

14) Bristow, C. M. (1966). A new graphical resistivity technique for detection of air-filled cavities, Studies in speleological. 7: 204-227.

15) Bates, E. R. (1973). Detection of subsurface cavities. U.S. army engineer waterways experiment station, Misc. Pap., S-73-40, pp. 63.

16) Fountain, L. S., Herzig, F. X. and Owen, T. E. (1975). Detection of subsurface cavities by surface remote sensing techniques, Federal Highway Admin .Report FHWA-RD-75-80p.

17) Greedy, D. P. (1975). Resistivity over caves: Bull. British Cave research Assn. 9: 5-6.

18) Myers, J. O. (1975). Cave location by electrical resistivity measurements, some misconceptions and practical limits of detection, Trans., British Cave Research Association, 2. p. 167-172.

19) Kirk, K. G. and Werner, E. (1981). Handbook of geophysical cavity-locating techniques with emphasis on electrical resistivity, Federal Highway Admin, Publication FHWA-IP-81-3.
20) Ushijima, K., Mizunaga, $H$. and Nagahama, $S$. (1989). Detection of cavities by the misa-a-la- masse and pole-dipole resistivity surveys, Proc. MMIJ/ IMM Symposium, p. 125-128.

21) Elawadi, E., El-Qady, G., Salem, A., and Ushijma, 2001. Detection of cavities using pole-dipole resistivity technique. Memoirs of the Facility of Engineering, Kyushu University, 61(4), pp 101-112.

22) Loke, M. H. and Dahlin, T. (2002). A comparison of the Gauss-Newton and quasi-Newton methods in resistivity imaging inversion, Journal of Applied Geophysics. 49:149-162.

23) Claerbout, J. F. and Muir, F. (1973). Robust modeling with erratic data. Geophysics, 38:826-844.

24) Geotomo Software. (2004). RES $2 D I N V$ ver.3.56.22, Rapid 2-D resistivity \&IP inversion using the least -squares method, geoelectrical imaging 2D\&3D Penang,Malaysia,133p.

25) Loke, M. H. (2000). Electrical imaging surveys for environmental and engineering studies, A Practical guide to 2-D and 3D surveys. P: 67.

26) Loke, M. H. and Barker, R. D. (1996). Rapid leastsquares inversion of apparent resistivity pseudosection by a quasi-Newton method, Geophysical Prospecting. 44:131-152. 